\title{
ACCIDENTAL PARASITISM OF A TICK BY A TICK
}

\author{
By George Anastos \\ Biological Laboratories, Harvard University
}

A case of a tick feeding on another tick was recently observed amongst a lot of several thousand ticks taken off domestic animals in the Netherlands East Indies, and sent for study by Dr. F. C. Kraneveld of the Bacterioloog Veeartsenijkundig Instituut, Buitenzorg, Java. A partially engorged female Rhipicephalus hæmaphysaloides paulopunctatus Neumann had its hypostome deeply inserted in the ventral surface of the abdomen of a fully engorged female Boöphilus microplus (Canestrini). The vial containing these two specimens listed the host as a cow from Batavia, Java; so it would appear that the Boöphilus was attached and feeding on the cow at the time it was collected.

This should be considered a case of accidental parasitism. It cannot well be called "cannibalism" since it involves ticks not only of different species but even of different genera. The cases called "cannibalism" by previous authors concerned individuals of the same species only.

A survey of the literature has revealed the following cases known as "cannibalism"': C. A. Barber (1895, Nature 52, p. 199) figures a male Amblyomma variegatum (Hyalomma venustum) attached to the posterior end of a female of the same species. Hunter and Hooker (1907, Bur. Ent. Bull. 72, p. 35) reported finding in a lot of live ticks from southwest Texas a female cattle tick, Boöphilus annulatus, with its mouthparts inserted in another tick (sex not given). Hooker, Bishopp, and Wood (1912, Bur. Ent. Bull. 106, p. 32) found amongst specimens sent to their laboratory a male Boöphilus annulatus (Margaropus annulatus) with its hypostome inserted into the side of an engorged female. Wood in two instances observed in the laboratory Ornithodoros turicata adults attaching and feeding on recently fed adults of the same 
species. Their final record was of two female Dermacentor andersoni (Dermacentor venustus) taken off a horse at Lakeside, Washington; when received in the laboratory the smaller female was attached to the more fully engorged one. Sergent (1930, Bull. Soc. Hist. Nat. Afr. du Nord XXI, p. 195) observed, in tick feeding experiments on a calf, that an unengorged nymph of Hyalomma mauritanicum attached itself to an engorged nymph of the same species. Roubaud and Colas-Belcour (1935, Ann. Parasit. Paris, T13 No. 5, p. 427) record two males of Aponomma crassipes on a female of the same species taken off a lizard in Tonkin, Indo-China. E. Francis (1938, Pub. Hlth. Rep., U. S. Pub. Hlth. Serv. 53, p. 2234) records a starved female Ornithodoros turicata attached and feeding on a fully engorged male, and an unfed fourth stage nymph feeding on a fed nymph of this same species. G. E. Davis (1941, Journal of Parasitology 27, p. 432) believes the term "cannibalism" to be a misnomer since the tick host is not consumed nor harmed enough to interfere with its normal functions. He records two cases wherein last stage nymphs of Ornithodoros parkeri were punctured by ticks which proceeded to completely engorge.

From the small number of known cases it would appear that ticks seldom feed on each other. Lack of a suitable host in nature might induce a tick to feed upon an already engorged tick; or else a tick might accidentally pierce another tick if the host were heavily infested. 

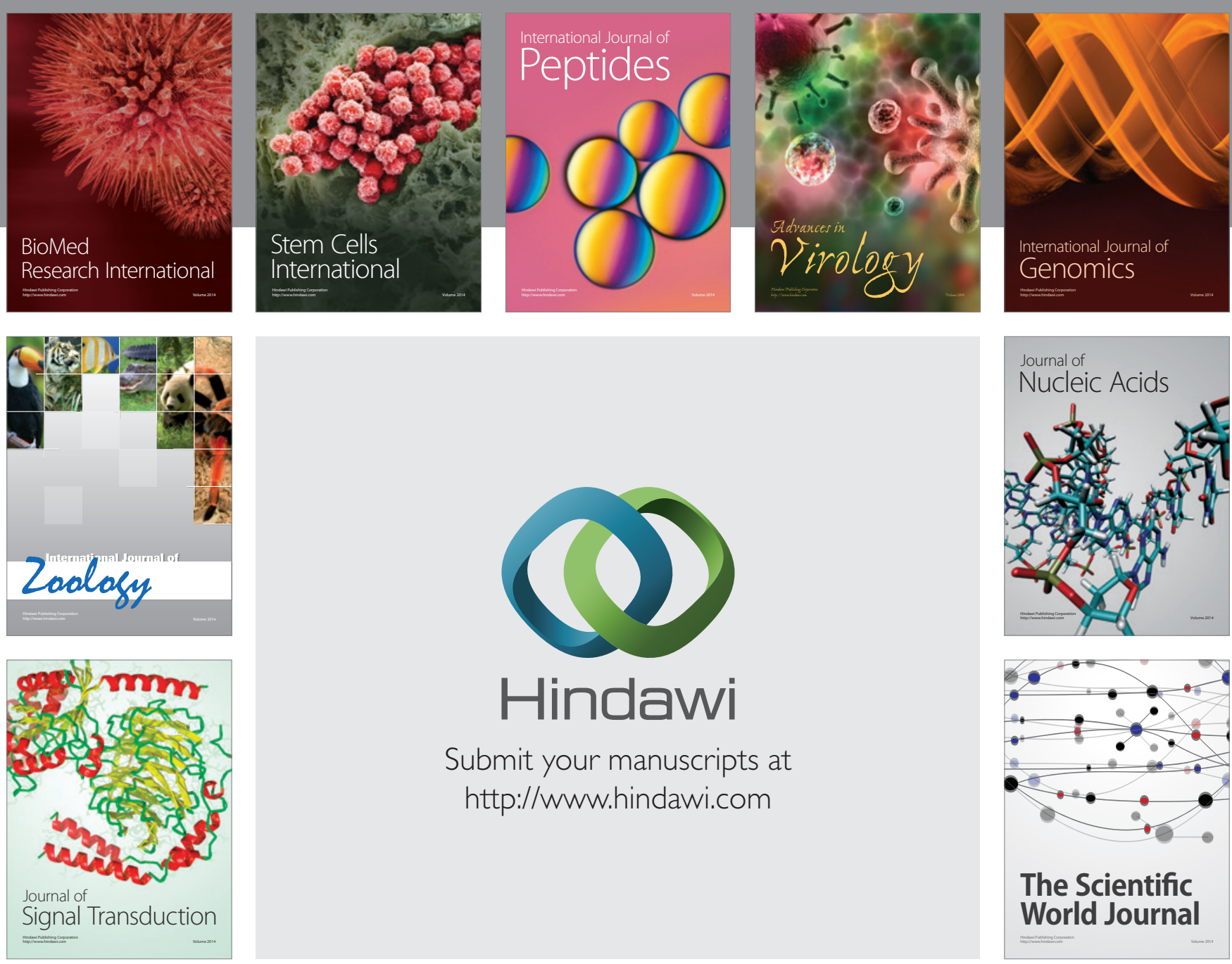

Submit your manuscripts at

http://www.hindawi.com
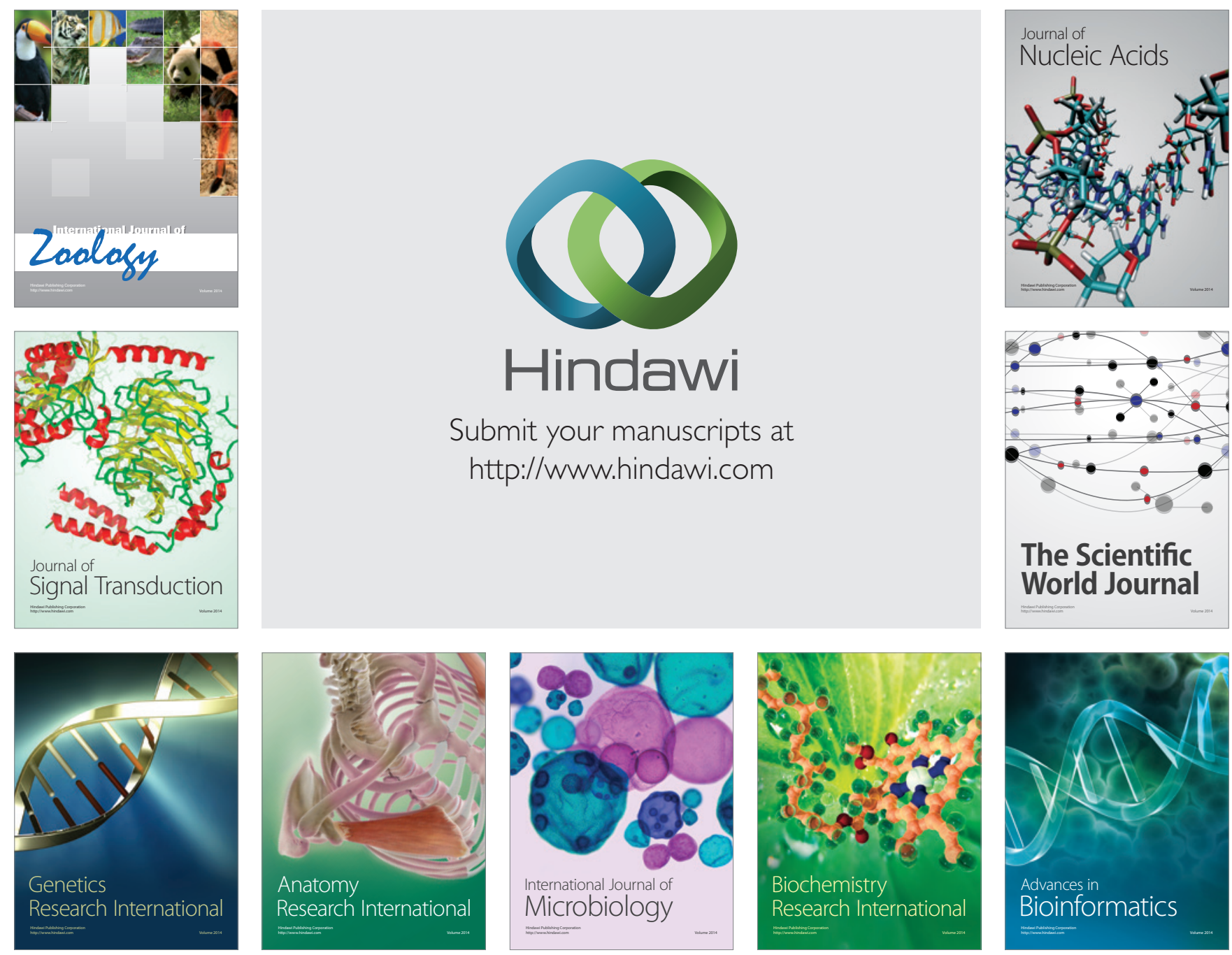

The Scientific World Journal
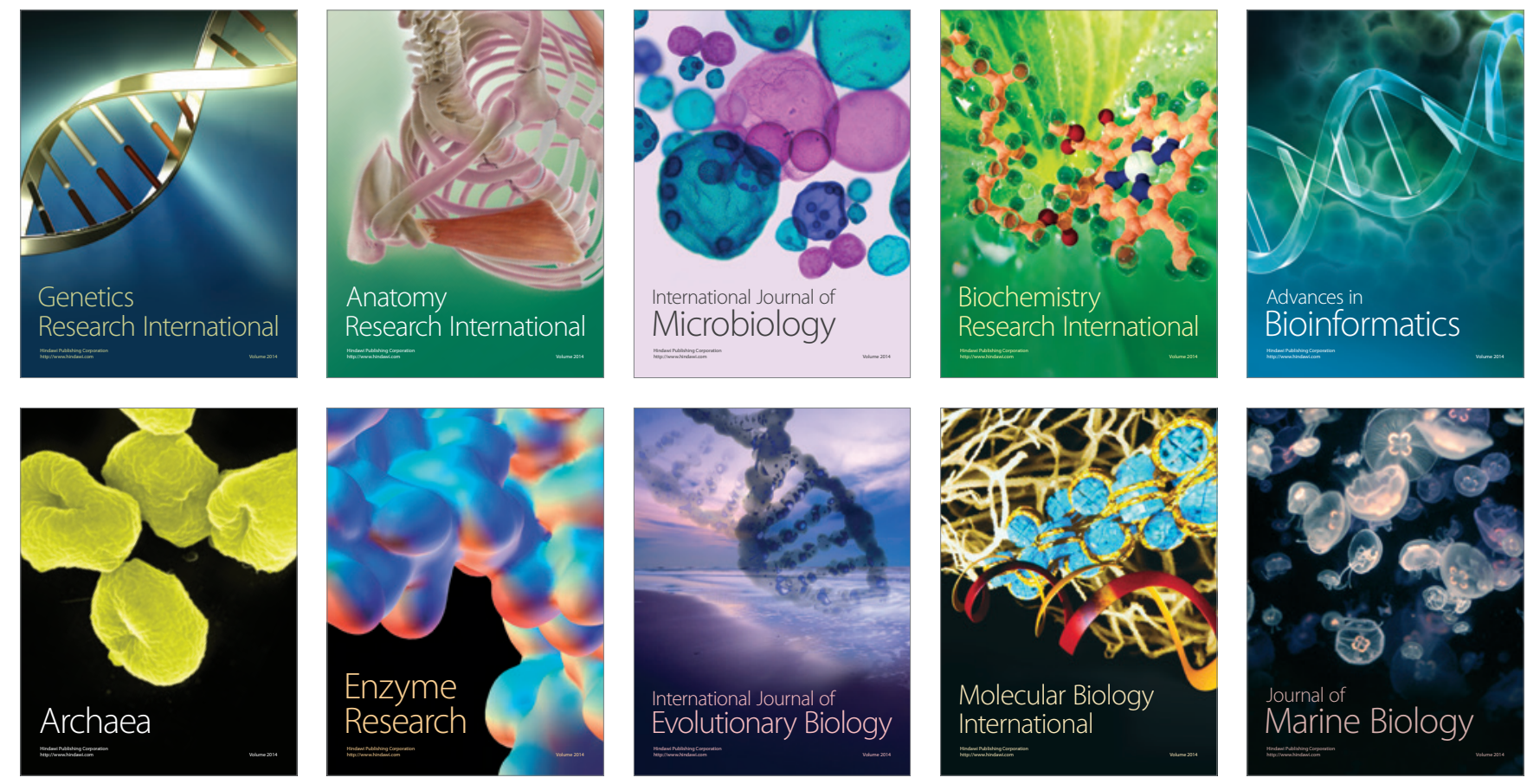